\title{
LA POSICIÓN RUSA HACIA MÉXICO EN VÍSPERAS DE LA GUERRA DE 1847
}

Evgueni Dik*

\section{La importancia de este tema se ex-} plica debido al desastroso carácter del conflicto bélico entre México y Estados Unidos, asi como a sus grandes consecuencias políticas, ideológicas y económicas, tanto para México como para su vecino del norte. Si bien la política mexicana y la norteamericana cuentan con una larga tradición de estudio al respecto, la postura de las grandes potencias de la época frente a este conflicto aún espera una investigación profunda y sólida.

A lo largo de la primera mitad del siglo XIX las posesiones rusas en América se ubican en la frontera con México. El establecimiento ruso de facto en el territorio mexicano (Fort Ross en California, 18121841), la incipiente colonización, así como el pujante comercio ruso en esta zona permiten apreciar la importancia de la postura rusa hacia México. Rusia no reconoció la independencia mexicana a pesar de los intentos de los oficiales de la Compañía Rusa-Americana por lograr un acuerdo de reconocimiento de jure. Tampoco prosperó la regulación formal del comercio ruso-mexicano.

Por cierto, la postura ultraconservadora del emperador Nicolás I explica en parte este fracaso, pero asimismo no se puede perder de

* Departamento Académico de Estudios Internacionales, ITAM. 


\section{EVGUENI DIK}

vista la inestabilidad política mexicana. La apreciación rusa de México como un país donde se mostraba patente la decadencia republicana determina su visión de la guerra de 1847, como un enfrentamiento entre una vigorosa nación en contra de un turbulento y anárquico país, una especie de "Polonia latinoamericana".

Los rusos se retiran de California hacia 1841, y en la venta de sus posesiones en esta área a un ciudadano norteamericano puede verse un posible avance de la cooperación rusa-norteamericana en América, así como el declive del virtual interés geoestratégico y comercial de México para Rusia.

Así, mientras la actitud rusa hacia México en vísperas de la guerra era poco benevolente, las relaciones ruso-norteamericanas se mostraban buenas y estables. Esta extraña amistad entre la autocracia rusa y la democracia norteamericana se fundamentaba no tanto en el desdén común hacia México, sino por una serie de controversias que ambas mantenían con Gran Bretaña. El destino de México poco preocupaba a los estadistas rusos, mientras que la fortaleza y el crecimiento de los Estados Unidos se veía como un factor positivo para apoyar los intereses rusos en Alaska en contra del Canadá británico. Definitivamente, la postura rusa se caracterizaba por una fuerte dosis de pronorteamericanismo y una percepción negativa de la República Mexicana.

$$
* * *
$$

Rusia imperial en la época de Nicolás I (1825-1855) alcanzó sin duda el cenit de su grandeza. Sin embargo, la decadencia de su sistema económico feudal era irreversible. El impresionante imperio y el ejército más grande del mundo convivían con estructuras arcaicas de servidumbre que afectaban el desarrollo de la economía y la sociedad rusas.

Los intereses estratégicos del Imperio ruso se centraban en Europa y en Asia. Rusia mantenía firme su postura de "Gendarme de Europa", mientras que para la década de los años 1840 continuaba su expansión hacia el Medio Oriente, hacia los estrechos, dando nuevo impulso a toda la problemática de la "Cuestión de Oriente". Nicolás I estaba 
obsesionado con la idea de poner fin a la agonía del "Hombre Enfermo de Europa", tratando de actuar en la cuestión de la herencia turca de acuerdo con Londres, cuya entente cordiale con la Francia orleanista ya se había hundido en 1846 . En este contexto, se da un paulatino acercamiento entre Rusia y Gran Bretaña.

Las fronteras rusas se extendían no sólo de Polonia a Kamchatka, sino que también se ubicaban en el continente americano.

El expansionismo ruso en el Pacifico septentrional se remonta a la segunda mitad del siglo XVIII. Con la fundación de la Compañía Rusa-Americana en 1799 , el creciente movimiento comercial hacia América de los empresarios rusos dedicados al floreciente comercio peletero (promychleniki) recibe el apoyo decisivo por parte del gobierno imperial. ' Con la presencia en Alaska y en las costas noroccidentales del continente americano, los rusos se sitúan en peligrosa cercanía de las posesiones españolas en América, poco protegidas y mal cuidadas. ${ }^{2}$ Estas circunstancias propulsaron el interés geoestratégico ruso por México y en especial por California.

A lo largo de la primera década del siglo XIX los rusos logran penetrar en la Alta California, primero como comerciantes y explotadores de los recursos peleteros, pero en 1812 fundan una colonia, Fort Ross, en la región de la Bahía de Bodega, que rebautizarán como la de Rumiantsev (en honor del ministro de Relaciones Exteriores ruso de la época), cerca del puerto de San Francisco, la posición española más al norte en esta región. Para la década de los años 1830 , el

' Vid, R. V. Makarova, Russkie Na Tijom Okeane vo Vtoroi Polovine XVIII v., 1968, Moscú, Nauka. (Los rusos en el Pacífico en la segunda mitad del siglo XVIII). Vid, edición en inglés: Russians on the Pacific, 1743-1799, 1974, Kingston, The Limestone Press. Glynn Barratt, Russia in Pacific Waters, 1715-1825. A Survey of the Origins of Russia's Naval Presence in the North and South Pacific, 1980, Vancouver, University of British Columbia Press.

${ }^{2}$ Vid. Al respecto: Ana María Schop Soler, Las relaciones entre Rusia y España en la época de Carlos IV, 1971, Barcelona, Úniv. de Barcelona, p. 80-3. 


\section{EVGUENI DIK}

empuje ruso hacia el Pacífico se debilitó. Sin embargo, Rusia mantenía vigentes sus intereses estratégicos, expansionistas y comerciales en el Septentrión del Pacífico. Desde 1812 Rusia era la única potencia europea con presencia territorial en las costas californianas (después del colapso colonial español). Pero a pesar de esta presencia en América sólo mantendrá relaciones diplomáticas con Estados Unidos a partir de 1808 y con el Imperio de Brasil desde 1828. El gobierno ruso después del Congreso de Viena basaba su política exterior sobre los principios de "legitimidad" y por lo tanto se negó terminantemente a entablar relaciones diplomáticas con las repúblicas hispanoamericanas.

Sin embargo, dada su presencia colonial y comercial en el territorio mexicano, Rusia no podía ignorar la existencia de este enorme país. Por otro lado, su visión de América Latina se basaba en el profundo interés manifiesto en la opinión pública rusa con respecto a las luchas por la independencia en la región.

$* * *$

El destino de México, la república latinoamericana más grande de aquel entonces y de facto el vecino de Rusia en América, no pasaba desapercibida para los viajeros, los funcionarios y los oficiales rusos ligados con la Compañía Rusa-Americana. Por lo tanto, para la década de los años 1840 y en vísperas de la Guerra de 1847 se formó una sólida y bien fundada percepción de México en Rusia, tanto en las esferas gubernamentales como en el sentir de la opinión pública.

Es importante destacar al mismo tiempo un vivo y bien motivado interés ruso por los Estados Unidos. Su independencia fue apoyada por Catalina la Grande, por medio de la política de "Neutralidad Armada"; desde finales del siglo XVIII, Rusia y Estados Unidos mantenían buenos y amistosos vínculos comerciales, culturales y más tarde políticos. Los Estados Unidos se veían como un vigoroso emporio comercial, el país amigo de Rusia. Esta extraña amistad de la monarquía autocrática y de la república norteamericana se puso de manifiesto en dos contiendas en las que participaron ambas naciones por 


\section{LA POSICIÓN RUSA HACIA MÉXICO}

separado. Mientras que Estados Unidos invadió México entre 1846 y 1848; Rusia al ocupar territorios pertenecientes al Imperio otomano en 1853, provocó la guerra de Crimea, la cual se extendió hasta 1856. En ambas conflagraciones la conducta de las dos potencias fue de neutralidad benévola hacia la otra.

Para México la relación con Rusia formó parte de la herencia de la política de contención novohispana, en contra del empuje ruso hacia California. ${ }^{3}$ La existencia legal de Fort Ross - fundado en 1812 en territorio español - mediante su adquisición a los indígenas de la región por parte de la Compañía Rusa-Americana, nunca fue reconocida por Madrid ni más tarde por México. El gobierno del México independiente consideraba la presencia de esta factoría comercial y económica rusa como una amenaza mucho más grave para la integridad territorial del país que el flujo de la inmigración de los colonos norteamericanos a través de las Rocallosas. Probablemente esta percepción se explicaba por el hecho de que la Compañía Rusa-Americana y su fundación en California dependían de San Petersburgo, la capital del poderoso Imperio de los zares, mientras que los free lancers norteamericanos carecían de protección estatal alguna y se veían como simples aventureros.

En vísperas del colapso del Imperio español en América, el gobierno del zar no mostraba simpatía alguna con la causa de los rebeldes, pero tampoco tuvo intención de obstaculizar el movimiento emancipacionista, viendo la causa española completamente perdida. De hecho ya para 1824 el canciller ruso Nesselrode reconoció la pérdida por España de sus colonias consideradas en consecuencia por Rusia como estados soberanos, sin que esto implicara establecer relaciones diplomáticas. ${ }^{4}$

${ }^{3}$ Juan Francisco Azcárate, Un programa de política internacional, 1932, México, SRE, p. 39. Archivo Histórico de la Secretaría de Relaciones Exteriores de México C-3-3-1, fols. 77-81 y fol. 51.

${ }^{4}$ E.A. Larín, "Rossia i voina za nezavisimot narodov latinskoi Ameriki", I Kollokvium istoricov SSR i Meksiki, 1990, Moscú, Instituto de América Latina, p. 115. ("Rusia y la guerra por la independencia de los pueblos de América Latina", Primer Coloquio de los historiadores de la Unión Soviética y México.) 
EVGUENI DIK

Esta postura respecto a México permitía a Rusia mantener por tiempo indefinido sus posesiones en California sin entrar en pláticas "formales" con México, cuyo gobiemo no reconocía, pero con el cual mantenía comercio y compartía una frontera. Por su parte, el gobierno mexicano desde 1824 reanudó la antigua exigencia española de abandonar el establecimiento Ross. ${ }^{5}$ Los rumores sobre la amenaza rusa para la joven independencia mexicana eran exagerados tanto por los norteamericanos como por Londres. La sombra de la amenaza del expansionismo ruso en América fue uno de los pretextos esgrimidos por el gobierno de los Estados Unidos para proclamar la Doctrina Monroe. Vale la pena mencionar que el gobierno ruso y los oficiales de la Compañia Rusa-Americana comprendían perfectamente bien la debilidad y el vacío geoestratégico mexicano en California. Así, durante la lucha por la independencia de México y debido al rápido colapso del Imperio de Iturbide, un ambicioso oficial de la Compañía RusaAmericana, Dimitrii Zavalishin, esperaba aprovechar la anarquía que reinaba en México para poner a California bajo una especie de protectorado ruso y llevar a cabo una activa política expansionista en América. Durante su estancia en California empezó a maquinar un complot entre los misioneros franciscanos con el propósito de afianzar el establecimiento de Rusia en la región. Zavalishin presentó su proyecto a Alejandro I y más tarde a Nicolás $I,{ }^{6}$ pero no prosperó dada la falta de interés del gobierno ruso en ampliar los dominios al sur de Oregón, ya que esto implicaba involucrarse en conflictos no sólo con Gran Bretaña sino también con los Estados Unidos. Para finales de la década de 1820 Rusia abandonó sus intereses en Oregón, lo que facilitó el paso para la colonización del occidente americano por los colonos

${ }^{5}$ Carta del ministro de Relaciones Exteriores de Rusia K.V. Nesselrode al ministro de Hacienda E.F. Kankrin, 15 (27) de octubre de 1824, apud, Martha Ortega y Alexander Sisonenko (eds.), México y Rusia en la primera mitad del siglo XIX, selección documental, 1990, México, SRE, p. 66.

${ }^{6}$ Viktor Petrov, Ruskie v istorii Ameriki, 1991, Moscú, Nauka, p. 96-7 (Los rusos en la historia de América). 


\section{LA POSICIÓN RUSA HACIA MÉXICO}

estadounidenses. Zavalishin, involucrado en el complot revolucionario de los decembristas que fracasó en 1825 , sería confinado a Siberia, pero su proyecto fue el único y real intento ruso de apoderarse de California.

El gobierno mexicano, sin duda alguna, habría sido incapaz de frenar un intento de la conquista rusa de California, razón por la cual tanto las autoridades en California como la diplomacia mexicanas buscaban normalizar las relaciones con los rusos. A principios de 1826, el diario oficial Águila Mexicana expresaba su confianza en que dada la cercanía de las posesiones rusas, tarde o temprano Rusia y México iban a establecer relaciones oficiales. La postura mexicana respecto a los rusos en California no era completamente hostil. Pese al rechazo formal de reconocer la presencia rusa en esta provincia, la Compañía Rusa-Americana mantenía unas relaciones comerciales por las que obtenía todo tipo de productos alimenticios de California. El gobernador de la Alta California, Manuel Victoria (1830-1831), informaba que los colonos rusos "eran buena gente" en comparación con los norteamericanos. 7 La crisis texana obligó al gobierno de la República a montar una política de contención de la colonización extranjera en California, tanto norteamericana como rusa. Pero el gobierno mexicano carecía de recursos reales para enfrentar el flujo de inmigrantes en la región. Manuel Victoria y su sucesor José Figueroa (1833-1835) proyectaban algunas restricciones legales sobre las licencias de explotación de los recursos peleteros de que gozaban los rusos desde la época de la Corona española. El hecho de que existieran estas licencias y el augctel floreciente comercio ruso-mexicano en California demuestran que a pesar de los deseos de obligar a los rusos a abandonar sus establecimientos, las autoridades mexicanas tenían que reconocer de uno u otro modo y de manera formal la presencia territorial rusa en la región.

La población de Fort Ross, era de cerca de doscientas personas en la década de 1830 , de las cuales sólo la cuarta parte eran rusos y el

${ }^{7}$ Documento 73, apud, La frontera ruso-mexicana: 1808-1842, recopilación, estudio y notas de Miguel Mathes, 1990, México, SRE, p. 182. 
EVGUENI DIK

resto mestizos, mientras que el número de indígenas ortodoxos no crecía. La servidumbre que reinaba en Rusia hacía difícil la tarea de llevar a cabo la colonización de vastos espacios de Siberia, mucho más aún la del continente americano. A su vez tampoco prosperaba la colonización mexicana en la zona, a pesar de los intentos de la colonización civil después de la expropiación de los bienes de las misiones por el gobierno de Valentín Gómez Farias en 1833. Más bien sólo los colonos norteamericanos tenían la oportunidad de aprovechar la coyuntura y poblar California.

Por cierto, la disminución del interés ruso hacia California en los años 1830 no fue resultado de las medidas restrictivas de las autoridades mexicanas ni de la colonización norteamericana, sino de la extinción de los recursos peleteros, en gran parte debido a las actividades de los norteamericanos en la región, y de la baja rentabilidad de Fort Ross como punto de abastecimiento de trigo y centeno para Alaska. Sin embargo a partir de 1833 los rusos establecen alrededor de Fort Ross nuevas granjas, pertenecientes a los oficiales de la Compañía. En especial el rancho de Vasilii Jlebnikov, de 70 acres con molino y dedicado a la producción de trigo, y el rancho de 100 acres de Pietr Kostromitinov, comandante de Fort Ross (1829-1836). Más al norte de la Bahía de Bodega se instaló el rancho de Yegor Chernych, agrónomo moscovita y empleado de la Compañía, con muy buenos resultados en producción frutícola y vinícola. Chernych también estableció allí la primera estación meteorológica de California. Desde 1812 los rusos poseían portuario con astillero, el primero en California. Toda esta economía rusa se basaba en la cacería de la nutria marina, así como de la agricultura y el comercio con los colonos mexicanos, norteamericanos y de San Francisco (no es casual que a partir de 1852 Kostrovitinov se desempeñara como vicecónsul ruso en esta ciudad). ${ }^{8}$

${ }^{8} \mathrm{Vid}$, Sobre la población de Fort Ross y de los colonos rusos en California: E.O. Essig, "The Russian Settlement at Ross", California Historical Society Quarterly, $\mathrm{n}^{\circ} 12,1933$, p. 193. Petrov, op. cit. , p. 35-45, p. 63-5. 
Con el objeto de lograr un acuerdo que normalizase las relaciones que se desarrollaban en torno a su enclave en California, el gobierno mexicano buscó establecer relaciones diplomáticas con el Imperio ruso. La Compañía Rusa-Americana también demostraba interés en lograr un acuerdo formal con México. El conde Liven, embajador ruso en Londres, inició gestiones ante el ministro mexicano, Manuel Eduardo de Gorostiza.

Este sondeo estaba encaminado al establecimiento de relaciones diplomáticas entre México y Rusia en 1830. Lo anterior es una evidencia de que Rusia estaba interesada en mantener el comercio con México, lo cual fue visto con beneplácito por Lucas Alamán, ministro de Relaciones Exteriores.

Tampoco fue absolutamente intransigente y negativa la postura del propio emperador Nicolás I. Según el canciller ruso, conde Nesselrode, si bien el gobierno imperial no tenía prisa en establecer relaciones con México, estaba dispuesto a canalizar las actividades necesarias para "formalizar" las relaciones vía la Compañía Rusa-Americana."

En 1836 el barón Ferdinand Wrangel, ex gobernador de dicha Compañía (1831-1835), visita México en su camino de regreso a Rusia. En esas circunstancias José Figueroa, con quien Wrangel como gobernador estuvo en contacto directo, le propondría promover la firma de un convenio sobre comercio, navegación y amistad - que hubiera significado el reconocimiento oficial de México por parte de Rusiaa cambio del reconocimiento de las posesiones rusas en California. Sin embargo, Wrangel en ese momento carecía de autoridad para llevar a cabo un acuerdo de este tipo, dado que sólo había sido instruido por San Petersburgo para formalizar los vínculos comerciales con México y asegurar la permanencia de la zona controlada por los rusos en California. $^{10}$

${ }^{9} \mathrm{Vid}$, Héctor Cárdenas y Evgueni Dik, Historia de las relaciones entre México y Rusia, 1993, México, SRE-FCE, p. 82-7.

${ }^{10}$ Ibid., p. $87-8$. 
EVGUENI DIK

La inestabilidad política en México, la falta de coherencia rusa para negociar un acuerdo, así como la pérdida de interés de los directores de la Compañía respecto a sus poco rentables posesiones en California, ponía a la misión del Wrangel en aprietos. A Wrangel no le podía molestar la ambigua y rígida postura del propio gobernador Figueroa quien, siendo sincero amigo de los rusos californianos, tenía que llevar a cabo acciones en contra de sus actividades en la región. Así como, en su posición de funcionario público, también recordarle aún en 1833 la ilegalidad de la presencia rusa en territorio mexicano. En la capital mexicana Wrangel trató en vano entrevistarse con Santa Anna, quien en este momento se encontraba a la cabeza de las tropas que combatían a los rebeldes texanos. Después de largos intentos logró hacerlo con el oficial mayor del Ministerio de Relaciones Exteriores de México, José María Ortiz Monasterio, lo cual no condujo a resultado alguno. La muerte del presidente interino Miguel Barragán "enterró" por completo sus expectativas de lograr algún tipo de acuerdo con la parte mexicana. Wrangel asimismo debió enfrentarse a las intrigas que creaban en torno a su misión los representantes diplomáticos británicos y franceses, y sólo el apoyo del cónsul de Prusia en la ciudad de México,

106 Frederick von Herolt, le permitió superar la desconfianza mexicana. Las negociaciones que sostuvo Wrangel con Ortiz Monasterio y el nuevo presidente interino José Justo Corro, no pudieron atenuar la percepción negativa de Rusia como el poderoso rival mexicano en California, pues ninguno de los dos contaba con poderes reales para tomar decisiones sobre el establecimiento de las relaciones con Rusia. La supremacía del Congreso de la Nación significaba que en México no existía una autoridad real para llevar a cabo tan delicadas negociaciones con un poderoso país vecino, que además se negaba a reconocer formalmente a México. ${ }^{11}$

Para Wrangel era obvio que los falsos rumores sobre los proyectos de conquista rusa en California eran difundidos en ese momento por

${ }^{11}$ Sobre la misión de Wrangel: Vid. Ibid., p. 87-91. 


\section{LA POSICIÓN RUSA HACIA MÉXICO}

los ciudadanos norteamericanos en México para enmascarar sus propios planes expansionistas.

Wrangel dejó México frustrado y decepcionado. Su largo camino hacia la capital del país desde San Blas y Tepic, vía Guadalajara, fue la primera visita de un viajero ruso al interior del país. Las Memorias sobre su estancia en México fueron rápidamente publicadas en Rusia entre octubre y noviembre de 1836 en las páginas de la prestigiosa y popular revista de San Petersburgo Abeja Norteña, un año más tarde editadas como libro con el título De Sitka a San Petersburgo a través de México. ${ }^{12}$ Escritas en forma llana y amena permitieron al público ruso conocer un país lejano y al mismo tiempo cercano por las posesiones rusas. Antes de Wrangel en la prensa rusa se habían publicado varias noticias sobre México, recolectadas principalmente de la prensa francesa, alemana y británica, como también otras memorias de viajeros rusos en California. Pero sólo gracias a Wrangel el lector ruso se pudo formar una visión más completa de la situación política, económica y cultural de México por una fuente de información primaria.

Pese a sus elogios y pintorescas descripciones del paisaje, arquitectura, comida, limpieza de las ciudades o el interés mexicano por las artes plásticas, la percepción de Wrangel de México era en general bastante negativa, lo veía como un país decadente y corrupto, condenado al fracaso. Pensaba que las incesantes luchas políticas, las "ridículas revoluciones", el robo al tesoro público, la desconfianza total respecto de la "decadencia de la dignidad humana", acabarían con el país. Wrangel con gran simpatía reflexionaba sobre la gente sencilla de México, "cobrizos" que aún no estaban maleados y era fácil gobernar. También observaba que el país carecía de "las órdenes de buenos oficiales". ${ }^{13}$ Como capitán de la Armada Imperial, se sorprendió por el bajo espíritu combativo y la moral relajada de las tropas mexicanas, a las que ve con aspecto de maleantes. Wrangel opinaba que en un

${ }^{12}$ Vid, Ferdinad Petrovich von Wrangel, De Sitka a San Petersburgo a través de México, 1975, México, SEP.

${ }^{13}$ Ibid., p. 37. 


\section{EVGUENI DIK}

futuro México tendría todas las posibilidades de convertirse en uno de los países más ricos del mundo, pero que su situación actual era desastrosa: desequilibrio presupuestal, un ejército compuesto casi en su mitad por las mujeres de los soldados, convicto de robo y contrabando, sobre todo por parte de Santa Anna. En sus Memorias Wrangel afirmaba que el propio ministro norteamericano en México obtendría valiosa información, la cual serviría para los planes norteamericanos de apoderarse de toda California aprovechando la situación política de México.

Wrangel también se mostró muy escéptico sobre las perspectivas internacionales de México, observando intransigencia y "orgullo" desmesurado de parte de sus estadistas, una xenofobia generalizada de la élite política y al mismo tiempo la influencia adversa ejercida por Francia y Gran Bretaña, así como de la prensa, fácil presa de los sobornos norteamericanos. En su informe a la Dirección de la Compañía Rusa-Americana, Wrangel informó sobre una campaña anti rusa en la prensa mexicana, inspirada por la Legación británica y por norteamericanos residentes en México. Según Wrangel, México “sobrevaloraba la importancia de Fort Ross", aún cuando la presencia rusa en la región le permitía una mayor protección de los Estados Unidos. Visto desde esta perspectiva Rusia, a cambio, podría obtener la anexión de la Bahía de Bodega y la ampliación de su control territorial a veinte millas al Este de ésta. También aseguró que en un tiempo no muy lejano los Estados Unidos iban a apoderarse de toda la Alta California. $^{14}$

El escepticismo del Wrangel sobre la viabilidad internacional mexicana, dada su observación de las costumbres y prácticas políticas corruptas y la carencia de una visión estratégica por parte de la élite política le hacía concluir que sólo los extranjeros serían capaces de salvar a México de la ruina total. Incluso se alegró por el "tropezón" que sufrió Santa Anna en Texas, ya que el golpe que infligían a México los texanos, era en contra de la arrogante aristocracia y el clero

${ }^{14}$ Ibid., p. 157. 


\section{LA POSICIÓN RUSA HACIA MÉXICO}

xenófobo. Wrangel opinaba que las tirantes relaciones entre México y los Estados Unidos sobre Texas podrían ser aprovechadas por Rusia, en especial en caso de la anexión de Texas por los Estados Unidos. Según su apreciación en poco tiempo no sólo Texas y California, sino también Sonora formarían parte de la Unión Americana, dada la enorme cantidad de yanquis instalados en esas comarcas, así como también en San Francisco y Monterrey, que facilitaban a los Estados Unidos todo tipo de información sobre México. ${ }^{15}$

Más tarde el sucesor de Wrangel en la Compañía Rusa-Americana informaba sobre la llegada a las cercanías de Fort Ross de un considerable número de colonos norteamericanos, quienes podrían obstaculizar los planes para la expansión rusa en la región. ${ }^{16}$

Sin embargo, en el ambiente de vacío político en México y geoestratégico en California, los rumores sobre el proyecto de un virtual protectorado británico en California, junto con la avalancha inmigrante norteamericana, así como la falta de la rentabilidad del propio Fort Ross para la Compañía Rusa-Americana, sus directivos, de acuerdo con el gobierno de San Petersburgo, deciden vender Fort Ross en 1839. Ciertamente, la percepción de la inevitable ocupación de California por los norteamericanos, como el fracaso de la misión de Wrangel también incidieron sobre esta decisión. El propio Nicolás I se rehusó a aceptar toda discusión sobre el reconocimiento de México. A una tácita observación de Wrangel, de que incluso Prusia había reconocido a México y firmado un convenio comercial, Nicolás I replicó con la firmeza de un verdadero conservador: "Los alemanes anteponen el dinero al honor, yo antepongo el honor al dinero." 17

${ }^{15} \mathrm{Vid}$, Sobre la misión de Wrangel, Moisés González Navarro, Los extranjeros en México y los mexicanos en el extranjero: 1821-1970, 1993, México, El Colegio de México, 1, 170-1.

${ }^{16}$ Cárdenas y Dik, op. cit., p. 91.

${ }^{17} \mathrm{~K}$. Skalkovski, Vnechniaia politika Rossii y Poloyenie Inostranyj Derjav, 1897, San Petersburgo, A.S. Suvorin, p. 526 (La política exterior rusa y la situación de las potencias extranjeras). 
EVGUENI DIK

Si los contactos políticos resultaron ser completamente frustrados después de 1836, los vínculos comerciales y el interés cultural ruso por México se mantuvo pese a la retirada de Rusia de California en 1842. En 1845 Mazatlán fue visitada por un barco ruso con el propósito de adquirir víveres para las colonias rusas en Alaska. Alexander Markov, integrante de la misión, dejó interesantes recuerdos sobre México. Su relato no tuvo un objetivo particular en el país, pero trazó un vivo y pintoresco panorama sobre las costas tropicales de México y sobre el puerto, nunca antes visitados por un barco ruso. A principios de los años 1840 la expedición botánica de la Academia de Ciencias de Rusia visitó México. Es interesante mencionar que por aquel entonces Rusia exportaba a México varios productos textiles y proseguía su comercio con California comprando provisiones para Alaska. ${ }^{18}$

Pese a las propuestas a la administración de Fort Ross, las posesiones rusas en California no fueron adquiridas por el gobierno mexicano, sino vendidas al inmigrante suizo John Sutter por la cantidad de 30,000 dólares, que nunca llegó a pagar. Sutter fundó la ciudad de Sacramento y más tarde inundó California con colonos extranjeros, situación que puso en aprietos a las autoridades mexicanas. ${ }^{19}$

110 El suizo incluso amenazó de que ante un intento mexicano de expulsarlo, "proclamaría una república independiente", para lo cual no carecía de fundamentos. ${ }^{20}$ La caída de Fort Ross en manos no mexicanas, sin duda proporcionó un ambiente favorable para la expansión norteamericana en la región.

Mientras que para los rusos México se veía como un país decadente, impotente y poco confiable, dada su inestabilidad política, la visión rusa de los Estados Unidos, tanto por el gobierno imperial como por la opinión pública liberal y conservadora era bastante favorable. La expansión de los Estados Unidos se veía como un proceso natural,

${ }^{18}$ Cárdenas y Dik, op. cit., p. 94.

${ }^{19}$ González Navarro, op. cit., I, 289-293.

${ }^{20}$ Ibid., 291. 
algo favorable para la defensa de los intereses rusos en Alaska, en tanto que opuesto a las posibles presiones británicas.

El destino de México poco preocupaba al gobierno del zar; después de la venta de Fort Ross y en vísperas de la guerra de 1847, la opinión pública rusa de hecho era hostil a este país. En el mejor de los casos México se veía como un lejano lugar exótico y tropical, perdido en revoluciones interminables. Otro ruso, Platón Chijachov, hombre de gran cultura y visión conservadora que por esos años visitó varios países latinoamericanos, incluido México, refiriéndose a su destino exclamaba: "La única esperanza es la Providencia... ¿los dejará acaso perecer en luchas interinas antes de que ocupen su lugar en la lista del mundo civilizado?"21

El enfrentamiento de México con el "mundo civilizado" representado por los Estados Unidos fue esperado en Rusia, por lo menos desde la década de los años 1830. Las simpatías rusas estaban totalmente del lado norteamericano, encargado de castigar a este anárquico país, una especie de "Polonia latinoamericana". Al desatarse el conflicto, el canciller ruso señalaba a los diplomáticos norteamericanos en San Petersburgo, que los Estados Unidos "tenían muchos motivos de queja contra México", 22 recordando tal vez el fracaso ruso años antes de legalizar sus posesiones en California. Tanto el zar como Nesselrode expresaban su total simpatía con la "justa" causa norteamericana y estaban seguros de que México no abrigaba ninguna posibilidad de éxito. A su vez, el ministro norteamericano se apresuró a asegurar al emperador en la entrevista que sostuvo con éste en mayo de 1847, que Estados Unidos "no deseaba extender sus posesiones en detrimento de alguna otra potencia", sugiriendo que el conflicto con México no afectaría las posesiones rusas en América.

${ }^{21}$ Apud, M. Fainstein, Siguiendo las huellas de Colón, relatos de escritores, científicos y viajeros rusos y soviéticos sobre América Latina, 1990, Moscú, Progreso, p. 47.

${ }^{22}$ Vid. Frederick Merk y Lois Bannister Merk, La Doctrina Monroe y el expansionismo norteamericano, 1843-1849, 1966, Buenos Aires, Paidós, p. 153. 


\section{EVGUENI DIK}

El ministro norteamericano respondiendo a los elogios del zar respecto al triunfo militar norteamericano en México, le aseguró que era deseo de los Estados Unidos concertar la paz en "términos favorables". Cuáles fueran esos términos poco interesaba a Rusia, donde ya existía la firme percepción de que tarde o temprano México perdería no sólo Texas, sino también California y Sonora. ${ }^{23}$

La neutralidad hostil de Rusia contra México se reflejó en el hecho de que el Dr. José María Luis Mora, encargado por el gobierno mexicano de "actuar" como "director" de la política mexicana en Europa durante la guerra, "encontró todas las puertas cerradas" ante los agentes diplomáticos de Rusia en Londres. ${ }^{24}$

El Destino Manifiesto norteamericano encontraba buen entendimiento en Rusia imperial, que a su vez también desde hacía siglos buscaba llevar a cabo su misión histórica en los Balcanes. Al fin y al cabo el débil tenía que someterse a la fuerza. ¡Acaso era diferente el destino de Polonia, acaso era diferente el destino que le esperaba a Turquía!

Sólo un profundo reajuste de los intereses geopolíticos rusos en América tras la venta de Alaska y la "reapertura" de la importancia

112 estratégica de América Latina para finales del siglo XIX crearían un ambiente de acercamiento ruso-mexicano fructífero, que culminará con el establecimiento de las relaciones diplomáticas entre ambas naciones en 1890 .

${ }^{23}$ Ibid.

${ }^{24}$ Raúl Figueroa Esquer, "El doctor Mora y la neutralidad británica durante la guerra entre México y Estados Unidos", Secuencia. Revista de Historia y Ciencias Sociales, $\mathrm{n}^{\circ} 16$, enero-abril de 1990, México, Instituto Mora, p. $11-2 ; 20$. 
LA POSICIÓN RUSA HACIA MÉXICO

\section{Fuentes y bibliografía}

Archivo Histórico de la Secretaría de Relaciones Exteriores de México; C-3-3-1.

\section{Articulos}

Essig, E.O., "The Russian Settlement at Ross", California Historial Society Quarterly, $\mathrm{n}^{\circ} 12,1933$.

Figueroa Esquer, Raúl, "El doctor Mora y la neutralidad británica durante la guerra entre México y Estados Unidos", Secuencia, Revista de Historia y Ciencias Sociales, $n^{\circ} 16$, enero-abril 1990, México, Instituto Mora.

Larín, E.A., "Rossia i voina za nezavisimot narodov latinoskoi Ameriki", I Kollokvium istoricov SSR i Meksiki, 1990, Moscú, Instituto de América Latina ("Rusia y la guerra por la independencia de los pueblos de América Latina", Primer Coloquio de los historiadores de la Unión Soviética y México).

\section{Libros}

Azcárate, Juan Franciso, Un programa de politica internacional, 1932, México, SRE.

Barratt, Glynn, Russia in Pacific Waters, 1715-1825. A Survey of the Origins of Russia's Naval Presence in the North and South Pacific, 1980, Vancouver, University of British Columbia Press.

Cárdenas, Héctor y Evgueni Dik, Historia de las relaciones entre México y Rusia, 1993, México, SRE-FCE.

Fainstein, M., Siguiendo las huellas de Colón, relatos de escritores, científicos y viajeros rusos y soviéticos sobre América Latina, 1990, Moscú, Progreso.

González Navarro, Moisés, Los extranjeros en México y los mexicanos en el extranjero: 1821-1970, 2 v., 1993, México, El Colegio de México.

Makarova, R.V., Russkie Na Tijom Okeane vo Vtoroi Polovine XVIII v., 1968, Moscú, Nauka (Los rusos en el Pacífico en la segunda mitad del 


\section{EVGUENI DIK}

siglo XVIII). Vid, edición en inglés: Russians on the Pacific, 1743-1799, 1974, Kingston, The Limestone Press.

Mathes, Miguel, La frontera ruso-mexicana: 1808-1842, recopilación, estudio y notas de..., 1990, México, SRE.

Merk, Frederick y Lois Bannister Merk, La Doctrina Monroe y el expansionismo norteamericano, 1843-1849, 1966, Buenos Aires, Paidós.

Ortega, Martha y Alexander Sisonenko (eds.), México y Rusia en la primera mitad del siglo XIX, selección documental, 1990, México, SRE.

Petrov, Viktor, Ruskie v istorii Ameriki, 1991, Moscú, Nauka (Los rusos en la historia de América).

Shop Soler, Ana María, Las relaciones con Rusia y España en la época de Carlos IV, 1971, Barcelona, Univ. de Barcelona.

Skalkovski, K., Vnechniaia politika Rossii y Poloyenie Inostranyj Derjav, 1897, San Petersburgo, A.S. Suvorin (La política exterior rusa y la situación de las potencias extranjeras).

Wrangel, Ferdinand Petrovich von, De Sitka a San Petersburgo a través de México, 1975, México, SEP. 